\title{
Retraction Note: Use of Barbed Sutures in Bariatric Surgery. Review of the Literature
}

\author{
Manuel Ferrer-Márquez ${ }^{1,2} \cdot$ Ricardo Belda-Lozano $^{1,2} \cdot$ Alberto Soriano-Maldonado $^{3}$
}

Published online: 12 August 2016

(C) Springer Science+Business Media New York 2016

\section{Retraction Note: OBES SURG (2016) 26:1964-1969}

DOI 10.1007/s11695-016-2263-4

This article has been retracted as a result of double publication. A similarly worded paper was previously published by Dr. Marquez in February 2016 in the journal Cirugía Española. The Publisher and Editor-in-Chief have reviewed both papers and have determined that the degree of overlap is extensive.

The online version of the original article can be found at http://dx. doi.org/10.1007/s11695-016-2263-4.

$\triangle$ Manuel Ferrer-Márquez manuferrer78@hotmail.com

1 Department of Bariatric Surgery, Torrecárdenas Hospital, Almería, Spain

2 Department of General Surgery, Torrecárdenas Hospital, Almería, Spain

3 Department of Physical Education and Sport, Faculty of Sport Sciences, University of Granada, Granada, Spain 